\title{
Factors affecting the distribution of fish during receding flood in lower Irtysh: effects of water level and diurnal cycle
}

\author{
A. D. Mochek ${ }^{1}$, E. S. Borisenko ${ }^{1}$, D. S. Pavlov ${ }^{1}$, A. A. Chemagin ${ }^{2}$ and S. V. Budaev ${ }^{1 *}$ \\ ${ }^{1}$ Severtsov Institute of Ecology and Evolution, Russian Academy of Sciences, Moscow, Russia \\ 2 Tobolsk Complex Research Station, Ural Division of the Russian Academy of Sciences, Tobolsk, Russia
}

Received 3 February 2014; Accepted 21 December 2014

\begin{abstract}
Subarctic Siberian freshwater ecosystems are unique due to severe climatic conditions and strong seasonal changes of water supply, temperature and nutrient availability. In this work we evaluated the relative influence of the illumination level linked with the diurnal cycle, local environmental heterogeneity and water level changes during the receding flood on the distribution and migrations of fish in the Lower Irtysh basin. The data are based on hydroacoustic surveys conducted from boats in the main channel and long-term hydroacoustic recording from a stationary platform in a floodplain stream. The majority of the fish in the study area were represented by juvenile Cyprinidae. Illumination level is shown to have the strongest effect on fish density both in floodplain stream and near-surface areas of the main channel: fish tended to migrate at night and their density was always significantly higher at night. Effects of local ecological heterogeneity and the water level change were weaker: they affected the dynamic re-distribution of the fish. Daily reduction of the water level significantly influenced the intensity of fish migrations in a small floodplain stream, although with a 4 days lag. We suggest that the high environmental variability in lower Irtysh dampens local environmental effects on fish assemblages. Two-way (downstream and upstream) migrations of juvenile fish in a floodplain stream are documented, pointing the potentially important role of adaptive behavioural tactics.
\end{abstract}

Key words: Hydroacoustic / distribution / abundance / downstream migration

\section{Introduction}

The distribution of fish in freshwater habitats is affected by multiple abiotic and biological factors, such as hydrological regime, temperature, food resources, predation and competition. (Rosso and Quiros, 2009; Jackson et al., 2001; Lucas et al., 2001). It is never static and involves continuous movements, drift and migrations at various scales which change over time (e.g., seasonally) and during the diurnal cycle (Welcomme et al., 2006; Pavlov and Mochek, 2009). Large floodplain rivers are characterized by particularly complex patterns of fish migrations. Fish not only migrate longitudinally (up and down the main channel), but also laterally, i.e. in and out of the river tributaries, floodplain streams and various flooded areas (Welcomme et al., 2006; Nunn et al., 2010; Makrakis et al., 2012). Nonetheless, relatively little is known about the patterns and causes of fish distribution and their movements between the channel and lateral waterbodies (Hohausová et al., 2003; Nunn et al., 2010).

\footnotetext{
*Corresponding author: sbudaev@gmail.com
}

It is well known that the diurnal rhythm of illumination is one of the most important factors determining the intensity of fish downstream migration, which typically occurs in the dark (Thorpe and Morgan, 1978; Pavlov, 1994; Reichard et al., 2002). Nonetheless, illumination alone might not be the only determining factor: local and global environmental heterogeneity, hydrological conditions as well as other factors may also exert substantial effects on fish migration and distribution (Pusey et al., 1995; Amoros and Bornette, 2002; Hohausová et al., 2003; Rosso and Quiros, 2009). Continental subarctic water bodies, such as Siberian Rivers such as the River Irtysh, are particularly interesting albeit poorly studied in this respect due to relatively severe climatic conditions with strong seasonal (and often interannual) changes of the water temperature, nutrient availability and water supply (Lyozin, 1999; Vincent, 2008). Furthermore, these ecosystems are now experiencing ever increasing anthropogenic impacts at the local and global scales, including pollution, increasing water absorption and climate change (Hrkal et al., 2006). The need for responsible management and conservation dictate the urgency for the study of 
various environmental effects on fish distribution and abundance.

Among many possible causal factors, flooding is known to significantly affect patterns of fish migration (Fernandes, 1997; Agostinho et al., 2004; Rakowitz et al., 2008). However, many previous studies concerned relatively large-scale and long-term effects of the flood, basically involving the seasonal distribution and migration patterns within the framework of the flood pulse concepts (Junk et al., 1989; Fernandes, 1997; Wolter and Bischoff, 2001). Much less is known about possible local, direct and relatively short-term effects of the water level change on fish behaviour and distribution, especially the intensity of their downstream migration (Murchie et al., 2008). Local patterns of fish movement and distribution in the channel areas adjacent to the floodplain tributaries are also poorly studied (Nunn et al., 2010). However, such data are potentially important because nearshore and floodplain habitats represent the most productive element of the river ecosystem: many fish prefer to dwell, feed (Van den Brink, 1996; Ward et al., 1999; Lucas et al., 2001) and spawn (Nunn et al., 2007) there. This may be caused by difficulties linked with observation and recording of fish movements and distribution at the local scale because they cannot be easily dealt using standard sampling techniques. Telemetry and mass mark and recapture may be very difficult to use with small riverine fish and essentially impossible with early juveniles. Furthermore, due to various interferences (e.g., boat movements, air bubbles, vegetation, multiple sound reverberations, etc.) the use of common hydroacoustic methods has also been associated with serious problems in shallow waters (Simmonds and MacLennan, 2005). Fortunately, recent advances in hydroacoustic technology allowed successful use of echosounders in many kinds of these environments (Knudsen and Sægrov, 2002; Lucas et al., 2002; Brehmer, 2003; Tátrai et al., 2009).

In this work, we investigated changes in the distribution and density of fish in different parts of the main channel of the Irtysh River and a linked floodplain stream during the receding flood (diminishing water level) using hydroacoustic methods. The objectives of the study were: (1) to determine how local environmental conditions (combined gradients of depth, substrate, current pattern) affected fish density in shallow areas of the river; (2) to determine how these effects are modified by the diurnal rhythm (day:night cycle) and water level fluctuations during the flood; and (3) identify the principal spatial and temporal loci characterized by the maximum concentration of the migrating fish which would have serious implications for conservation and management. To do this we surveyed the distribution of fish in shallow areas of the Irtysh River and monitored local migrations of fish in the Varpak floodplain stream. In this work, we concentrated on shallow areas of the river and the receding flood because the downstream migration of young fish is often particularly intense at this time (Thorpe and Morgan, 1978; Pavlov, 1994; Reichard et al., 2002).

\section{Materials and methods}

\section{Study area}

This field study was conducted in June-July 2012 in a lower part of the Irtysh River basin, Uvatskii raion of the Tyumen oblast, Russian Federation $\left(58.731^{\circ} \mathrm{N} 68.70^{\circ} \mathrm{E}\right)$. This is a powerful river with the width of the channel up to $500 \mathrm{~m}$ and average depth in the waterway channel from 7 to $15 \mathrm{~m}$. The current speed here ranges from 0.45 to $1.1 \mathrm{~m} . \mathrm{s}^{-1}$ (Lyozin, 1999). The Gornoslinkino riverbed hollow, with a maximum depth $50 \mathrm{~m}$, is located in the Irtysh River channel (Fig. 1). It has the total area equal to $0.5 \mathrm{~km}^{2}$ (50 ha). The Varpak floodplain stream joins the main channel above the Gornoslinkino riverbed hollow, at the right bank of the Irtysh River (Fig. 1). Its length is $14 \mathrm{~km}$ and the width in the lower reaches was about $20 \mathrm{~m}$ during the high water and reduced to $5 \mathrm{~m}$ during low water, the depth for the most part was about $1 \mathrm{~m}$ (maximum $8 \mathrm{~m}$ ). During the high water period (first half of June, maximum water level) water was stalled (i.e., no stable current except wind-induced). However, at the end of the flooding, late July, it reached the maximum values about $1 \mathrm{~m} . \mathrm{s}^{-1}$. The Varpak dries out almost completely during the August low-water season. This work was conducted during the intense receding flood period, from the maximum water level (first days of June) to its stabilization (first days of July). We measured the water level daily using standard depth-gauge installed in the lower course of the Varpak stream (starred in Fig. 1). The total decrease of the water level during the study was $218.2 \mathrm{~cm}$. Water temperature in the Irtysh River during the study ranged from 23.0 to $24.5^{\circ} \mathrm{C}$.

Because the hydrological and environmental conditions in the Irtysh River significantly changes at the meander immediately upstream of the Gornoslinkino hollow, we specified two river zones: "upper" and "down" approximately at $68.696^{\circ} \mathrm{E}$ (Fig. 1). In the upper zone, the dominant currents tend towards the right bank (Fig. 1). The depth here is moderate, from 3 to $7 \mathrm{~m}$ at a distance 10-20 $\mathrm{m}$ from the riverside where the survey boat moved along the longitudinal transect. The down zone is characterized by a gyrating currents towards the left river bank and larger depths. For example, the transect depth (10-20 $\mathrm{m}$ from the bank) was $7-10 \mathrm{~m}$ at the left riverside and $15-20 \mathrm{~m}$ at the right riverside (Fig. 1). Such a division enabled the depiction of the most crucial elements of the local ecological heterogeneity. We expected to find higher density of juvenile fish at the right bank in the upper zone and at the riverbed hollow, which are characterized by higher depth and current speed, making them an ideal channel for downstream migration.

\section{Hydroacoustic surveys}

We used three types of echo-sounders: Ascor, Netcor and Pancor. These systems recorded the fish density: number of fish per hectare of water surface area. Ascor is a 


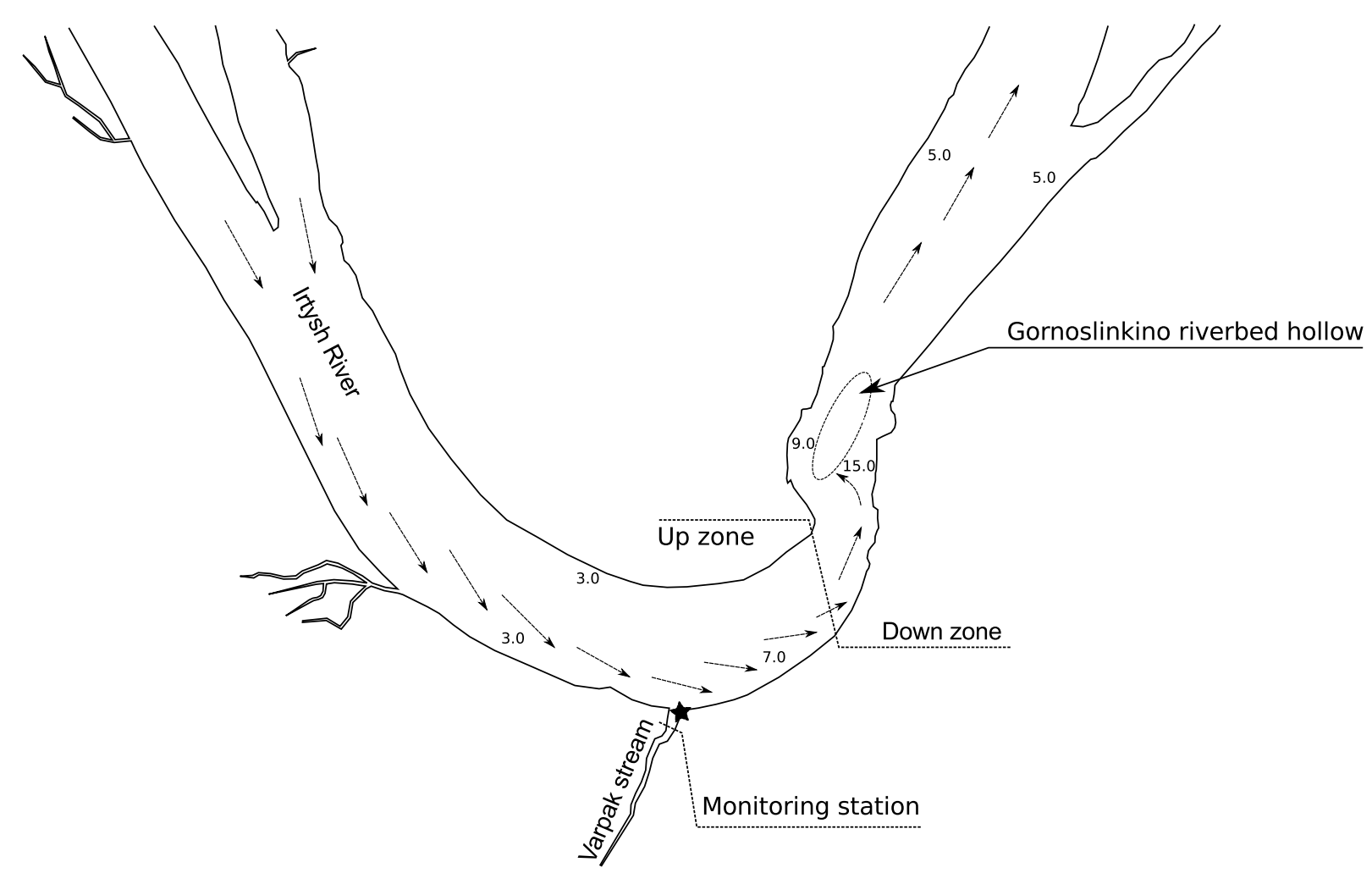

Fig. 1. Map of the study area. Solid arrows depict dominant currents, numbers in the rive show approximate depth under longitudinal transect. The asterisk near the monitoring station shows the position of the water level gauge.

modified downward oriented dual-beam research hydroacoustic system operating at 50 and $200 \mathrm{kHz}$ at depths 3-100 m. The beam pattern of Ascor at $3 \mathrm{~dB}$ at $46^{\circ}$ at $50 \mathrm{kHz}$ and is $14^{\circ}$ at $200 \mathrm{kHz}$, electric output of the transducer is $300 \mathrm{~W}$, impulse time ranges from 0.1 to $1.0 \mathrm{~ms}$, impulse frequency, from 10 to $0.5 \mathrm{~Hz}$. The system also included a global positioning system (GPS) receiver, an analogue to digital converter (14 bit, conversion frequency $40-400 \mathrm{kHz}$ ), managed by a portable computer. In this work, we applied it for pilot surveying of the study area using a systematic zigzag transect design from a vessel (Simmonds and MacLennan, 2005; Winfield et al., 2013). Ascor also allows identification of the fish families, based on the analysis of the enveloping curve for the echo signal returned from the fish swimbladder at the $50 \mathrm{kHz}$ and statistical modelling of the scatter (Borisenko et al., 2006; Pavlov et al., 2010; Frouzova et al., 2011). The taxonomic data analysed in this study are based on Ascor surveys.

Pancor is a scanning multi-beam side-looking hydroacoustic system, working at the frequency $455 \mathrm{kHz}$ (Borisenko, 2008; Kudryavtsev and Borisenko, 2009; Borisenko et al., 2011). Its operating depth is $0.5-3.0 \mathrm{~m}$, maximum operating distance $20 \mathrm{~m}$, view arc is $70^{\circ}$, the beam pattern of a single scanning beam is $10^{\circ}$, impulse frequency can range from 0.1 to $0.8 \mathrm{~ms}$, electric output of the transducer from 20 to $80 \mathrm{~W}$, sampling frequency up to $100 \mathrm{~Hz}$. The system includes a 14 bit analogue to digital converter, GPS unit, and was managed by a portable computer. Pancor could work in shallow places both in the horizontal mode and at any inclination of the transducer beam pattern. In this study, we used it in nearshore areas of the main channel of the Irtysh River and in the Gornoslinkino hollow area. Most of the data collected in the Irtysh channel that were analysed here are actually based on Pancor surveys; they included density and the fish size.

Discrimination of individual targets by Pancor was based on continuous analysis of the enveloping curve for the echo signal with noise filtered out. If the signal exceeded $1 / 2$ and $1 / 8$ of the amplitude (with respective impulse durations), it was measured and categorized. Signal was considered "noise" when the 1/2-amplitude impulse did not exceed the specific minimum duration. Single and multiple targets were identified based on the measured durations of the $1 / 2$ and $1 / 8$-amplitude impulse durations. This allowed simultaneous use of echocount and echointegration, measure the fish size (target strength) in a wide dynamic range, both within a time lag and at any depth layer in situ. Automatic recognition of the substrate with dynamic recalculation of the bottom discriminator allowed relatively precise identification and assessment of bottom-dwelling fish. The fish body size was calculated from the amplitude enveloping curves using log-linear regression equations determined for the mass fish species of the study basin previously (Borisenko et al., 2006, 1989). The acoustic parameters of the equipment (Ascor, Pancor and Netcor) were previously calibrated using a standard copper sphere $39.6 \mathrm{~mm}$ in diameter (see Simmonds and MacLennan, 2005). 
Hydroacoustic surveys with Pancor were conducted from a small boat 15 th and 16th June (high water) and 5 th and 6th July (low water) during the day (from 12:45 illumination level $>1000 \mathrm{~lx}$ ) and at night (from 22:00, illumination level $<101 \mathrm{x}$ ). We used two types of survey transects. First, longitudinal surveying was conducted to assess fish at the left and right shores of the Irtysh River. During such surveys the boat slowly moved along one of the riversides of the Irtysh at a distance 10-20 m from the bank, thereby forming a smooth longitudinal transect following the river course. The transducer during this time was directed to the nearest shore. The Gornoslinkino riverbed hollow was surveyed using a systematic zigzag transect design (Simmonds and MacLennan, 2005; Winfield et al., 2013) covering its whole area. The transect angles were actually large arches more than $20 \mathrm{~m}$ in diameter (Pancor maximum range), making zigzags more similar to the parallel design; additionally, the transducer always had the same direction relative to the river (i.e., overturned following the boat turn). This avoided the possibility of repeated sampling of the same fish at the angles of the transect. The geographical location of the boat and the current depth were continuously controlled (GPS and in-boat sonar monitor).

To assess the numbers and the sizes of the fish passing through a specific section of the Varpak floodplain stream, we used stationary Netcor hydroacoustic system (Pavlov et al., 2009), that was installed in its lower course (Fig. 1). This system represents an anchored floating platform with a high-frequency $(455 \mathrm{kHz})$ multi-beam side-looking transmitter immersed at $0.3 \mathrm{~m}$ in water. Basic operating characteristics of Netcor are as follows: scanning impulse duration $>0.4 \mathrm{~ms}$; electric output at the transducer is $40 \mathrm{~W}$; oscillation frequency is up to $12 \mathrm{~Hz}$; beam pattern at $6 \mathrm{~dB}$ is $10^{\circ}$; the width of the multi-beam viewport is $60^{\circ}$ in the hyperplane of the fan of beams; in the horizontal mode Netcor allowed stable operation at the depth at least $0.3 \mathrm{~m}$ with the maximum recording distance of a single fish with the target strength $-60 \mathrm{~dB}(<2 \mathrm{~cm})$ up to $20 \mathrm{~m}$. Note that the width of the Varpak stream in the location of the hydroacoustic platform did not exceed $12 \mathrm{~m}$. The system on the platform was connected to a remote controlling computer workstation over an ISM $2.4 \mathrm{GHz}$ radio channel providing for stable connection up to $200 \mathrm{~m}$. Netcor allows assessing the number, size and movement direction (downstream, upstream) of target fish.

Hydroacoustic data analysis included noise filtration and cluster analysis for discrimination of the fish signal from various reverberations (surface, bottom, water media heterogeneity due to debris and bubbles). As a result, it becomes possible to identify and track individual fish passing through the cross-section of the stream covered by the multi-beam transducer signal (e.g., fish id, movement direction, target strength). To identify the fish we used a method based on measuring the target strength by first emitting a wide beam while recording the signal with a narrow beam scanning within the broad beam pattern of the echosounder. As the fish moved through the crosssection, there were multiple cycles of the wide beam and scanning with the narrow beam and the software automatically discriminated high signals from individual fish. The fish size was calculated from the target strength using regression coefficients for local freshwater fish (Borisenko et al., 2006) taking account of the working frequency of the multi-beam system. The data on fish movements were recorded continuously $24 \mathrm{~h}$ a day during 1 month (from 6 th June to 7 th July). We directed the transducer $1 \mathrm{~m}$ from the left bank, so that it looked towards the deeper and steeper right side of the stream. Thus, nearly the whole section of the stream was covered.

\section{Statistical analysis}

As neighbouring measurements on the hydroacoustic survey are likely to be non-independent, we used mixed effect models for the statistical analysis (Pinherio and Bates, 2000), in which the sample id entered as a random effect. Mixed models were calculated using the lmer function from lme4 package in R (R Core Team, 2013); $P$-values of the Wald $F$ tests were computed via the Kenward-Roger approximation (Kenward and Roger, 1997; Type II P-values were calculated). The adequacy of the model was checked by examining plots of the residuals. For group comparisons, we used the Welch $t$-test. Skewness/kurtosis analysis (e.g., D'Agostino test) was performed using the $\mathrm{R}$ package moments. To investigate relationships between fish numbers over a time lag, we calculated auto- and cross-correlations. Geographical coordinates were converted to the UTM projection using the function conv $U L$ from the R package PBSmapping. In the text, we present means $\pm 95 \%$ confidence intervals.

\section{Results}

The pilot survey using Ascor (10, 11 and 26 June 2012, day 13:00 and night 23:30) indicated that most of the fish were species of the Cyprinidae family ( $>80 \%$ ). Fish of all other families, such as Percidae, Coregonidae and Esocidae, never exceeded $20 \%$ of the identified fish.

All data on fish density analysed here are based on Pancor surveys. A mixed effects model (Model 1) was constructed to investigate the effects on the fish density of (1) water level reduction during the flood progress (LEVEL, high water versus low water); (2) diurnal period (DIURN, day versus night); (3) riverside (SIDE, left versus right) and (4) river zone (ZONE, upper versus down). In this model, sample id was a random factor nested within the riverside (SIDE). The fish numbers demonstrated extreme skewness (skewness $=11.55$, D'Agostino test of skewness: $z=23.62 ; P<0.001)$. Therefore, the data were log-transformed to make them appropriate (skewness = 0.02 , D'Agostino test of skewness: $z=0.23 ; P=0.820$ ).

Three main effects were significant in the mixed model (Table 1, Model 1): DIURN, SIDE and ZONE. There were also two significant interactions: LEVEL $\times$ SIDE and DIURN $\times$ SIDE. The most conspicuous trend obvious in the data (Fig. 2) is that the fish density was always 
Table 1. Effects of different factors on fish density, Models 1 and 2.

\begin{tabular}{|c|c|c|c|}
\hline Effect & $F$ & d.f. & $P$ \\
\hline \multicolumn{4}{|l|}{$\overline{\text { Model } 1}$} \\
\hline LEVEL & 0.20 & $1,691.24$ & 0.652 \\
\hline DIURN & 116.15 & $1,710.19$ & $<0.001$ \\
\hline SIDE & 36.23 & $1,325.47$ & $<0.001$ \\
\hline ZONE & 30.19 & $1,595.34$ & $<0.001$ \\
\hline LEVEL $\times$ DIURN & 1.97 & $1,979.11$ & 0.161 \\
\hline LEVEL $\times$ SIDE & 28.03 & $1,682.92$ & $<0.001$ \\
\hline DIURN $\times$ SIDE & 5.79 & $1,700.14$ & 0.016 \\
\hline $\mathrm{LEVEL} \times \mathrm{ZONE}$ & 0.24 & $1,756.71$ & 0.626 \\
\hline $\mathrm{DIURN} \times \mathrm{ZONE}$ & 0.04 & $1,771.93$ & 0.843 \\
\hline RIVERAREA $\times$ SAREA & 1.34 & $1,505.47$ & 0.240 \\
\hline $\mathrm{LEVEL} \times \mathrm{DIURN} \times \mathrm{SIDE}$ & 1.14 & $1,975.14$ & 0.285 \\
\hline $\mathrm{LEVEL} \times \mathrm{DIURN} \times \mathrm{ZONE}$ & 1.91 & $1,977.32$ & 0.167 \\
\hline $\mathrm{LEVEL} \times \mathrm{SIDE} \times \mathrm{ZONE}$ & 0.43 & $1,758.73$ & 0.515 \\
\hline DIURN $\times$ SIDE $\times$ ZONE & 0.20 & $1,771.80$ & 0.658 \\
\hline $\mathrm{LEVEL} \times \mathrm{DIURN} \times \mathrm{SIDE} \times \mathrm{ZONE}$ & 3.55 & $1,971.97$ & 0.060 \\
\hline \multicolumn{4}{|l|}{ Model 2} \\
\hline LEVEL & 14.23 & $1,660.65$ & $<0.001$ \\
\hline DIURN & 187.46 & $1,630.97$ & $<0.001$ \\
\hline PART & 29.68 & $2,322.41$ & $<0.001$ \\
\hline LEVEL $\times$ DIURN & 0.17 & $1,831.24$ & 0.682 \\
\hline LEVEL $\times$ PART & 28.61 & $2,661.49$ & $<0.001$ \\
\hline DIURN $\times$ PART & 14.71 & $2,637.37$ & $<0.001$ \\
\hline $\mathrm{LEVEL} \times \mathrm{DIURN} \times \mathrm{PART}$ & 3.66 & $2,753.72$ & 0.026 \\
\hline
\end{tabular}

LEVEL, water level reduction during the flood progress (high water versus low water); DIURN, diurnal period (day versus night); SIDE, riverside (left versus right); ZONE, river zone (upper versus down); PART, river part (hollow, left and right riversides, three levels). Type II Wald $F$ tests with Kenward-Roger degrees of freedom (d.f.) are presented. See text for more explanations.
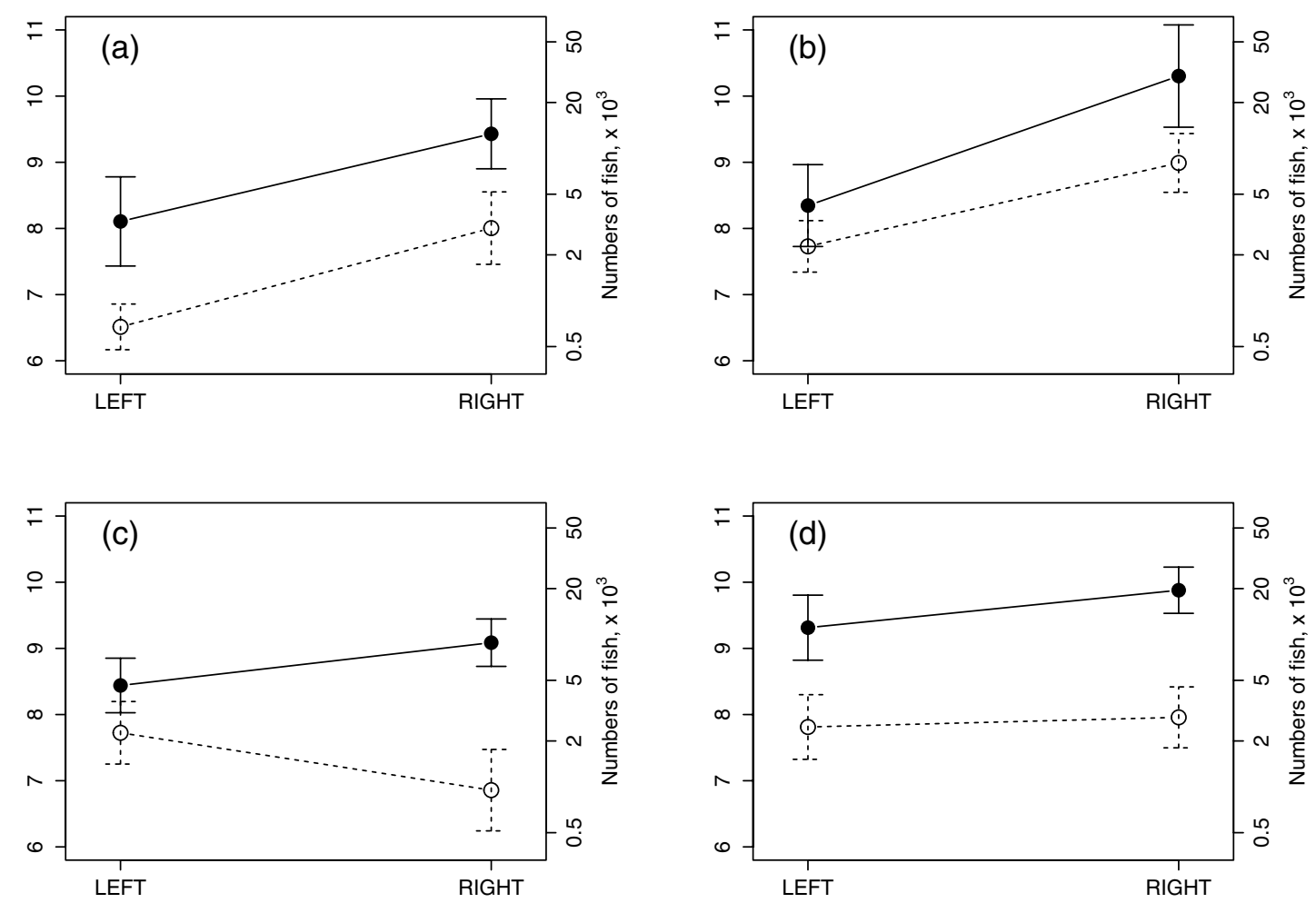

Fig. 2. Logarithm of the fish density for different levels of the model factors (Model 1). Solid lines with black circles point to night, dashed line with open circles depict day. LEFT and RIGHT refer to the riverside. Upper rows (a) and (b) refer to high water, and lower rows (c) and (d) refer to low water; left panels (a) and (c) refer to upper zone, right panels (b) and (d) to lower zone. Means and confidence intervals of log-transformed data are shown (left $Y$-scale). Right $Y$-scale depicts the absolute density of the fish ( $\times 10^{3} \mathrm{fish} / \mathrm{ha}$ ) back calculated from the logarithm. 

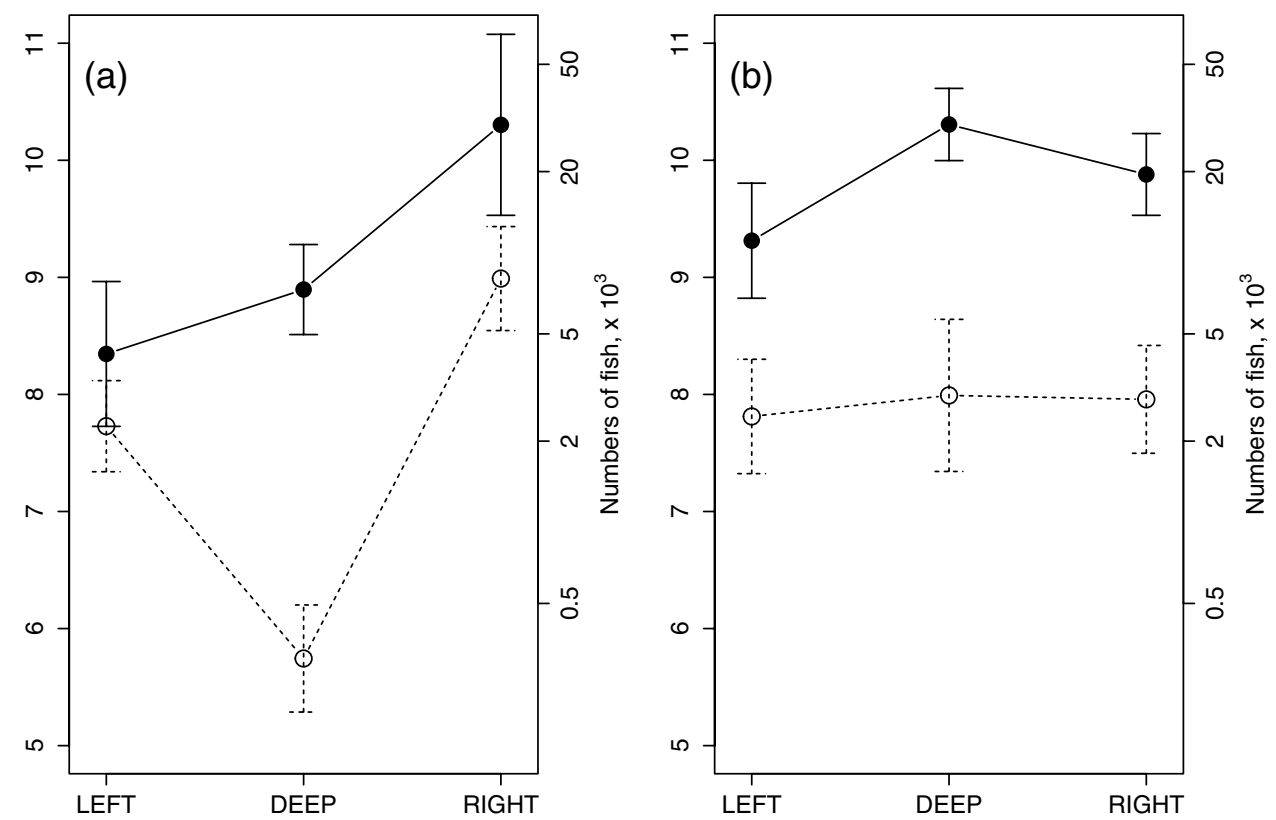

Fig. 3. Logarithm of the fish density for different levels of the model factors (Model 2). Solid lines with black circles point to night, dashed line with open circles depict day. LEFT and RIGHT refer to the riverside, DEEP to the Gornoslinkino hollow. Left panel (a) refers to high water; right panel (b) refers to low water. Means and confidence intervals of log-transformed data are shown (left $Y$-scale). Right $Y$-scale depicts the absolute values ( $\times 10^{3}$ fish/ha) back calculated from the logarithm.

significantly higher at night $(t=-8.91$, d.f. $=983.316$, $P<0.001)$ and in the down zone $(t=-5.01$, d.f. $=$ 989.006, $P<0.001)$. Overall, the fish density was higher at the right riverside $(t=-5.22$, d.f. $=970.934, P<$ 0.001 ), although it redistributed from day to night differently in the upper and down zones (Fig. 2). Importantly, reduction of the water level did not affect the overall fish density (no significant main effect, Table 1, Model 1), but changed fish re-distribution at the left and right riversides (interaction term significant).

To compare the number of fish at the left and right riversides with the Gornoslinkino hollow area we constructed another mixed model (Model 2). It accounted for the effects of (1) water level decrease during the flood progress (LEVEL, high water versus low water); (2) diurnal period (DIURN, day versus night); and (3) river system part (PART: left, right, hollow). As in the previous models, hydroacoustic sample ids were a random factor nested within the river system part (PART). We limited the analysis to the down zone because otherwise the riverside data would not be immediately comparable with the hollow. Again, logarithmic transformation was necessary to make data more appropriate for the analysis (untransformed data: skewness $=4.62, z=10.11, P<0.001$; log-transformed data: skewness $=-0.48, z=-2.30, P=$ 0.022 ). In the model, all main effects and the interactions except LEVEL $\times$ DIURN were significant (Table 1, Model 2). Again the numbers of fish at night significantly exceeded those during the day (Fig. 3; overall data: $t=-4.41$, d.f. $=303.338, P<0.001$ ). Interestingly, the numbers of fish at the hollow area tended to be rather low at high water especially during the day, however, elevated dramatically at low water especially at night (Fig. 3).
To determine the effects of the various factors (LEVEL, DIURN, SIDE and ZONE) on the size composition (based on Pancor surveys) of the fish at the riversides of the Irtysh River, we calculated a series of mixed models (Model 3) for the proportion of the fish in the following size classes: $0-3 \mathrm{~cm}, 3-5 \mathrm{~cm}, 5-7 \mathrm{~cm}$ and $>7 \mathrm{~cm}$ (separate models for each class were fitted). As the data for the first three size classes were more or less symmetrically distributed (maximum skewness $=0.88$ ), we did not use data transformations. But the largest size category $(>7 \mathrm{~cm})$ had a more skewed distribution (skewness $=1.22, z=8.40, P<0.001$ ) and we had to use the logit-transformation (Warton and Hui, 2011), resulting in more adequate data (skewness $=-0.28, z=-2.39$, $P=0.017$ ). All these models did not account for interactions and, again, sample id was a random factor nested in SIDE. The effects of the LEVEL, DIURN and SIDE were significant in all these models. Additionally, the effect of ZONE was significant for the size class $3-4 \mathrm{~cm}$ (Table 2).

Size composition of the fish is presented in Figure 4(a). Two patterns are clear here: firstly, the proportion of early juveniles $(<3 \mathrm{~cm})$ in nearshore areas of the Irtysh was higher during the day, whereas larger fish $(>5 \mathrm{~cm})$, at night. Secondly, the percentage of early juveniles $(<3 \mathrm{~cm})$ was higher at low water level, whereas larger fish $(>7 \mathrm{~cm})$, at high water level. As to the significant main effect of the riverside, smaller fish $(0-3$ and $3-5 \mathrm{~cm})$ predominantly occurred near the left riverside (left versus right, respectively: $41.7 \pm 1.1$ versus $36.0 \pm 1.3$ and $35.6 \pm 0.8$ versus $34.7 \pm 0.8)$, whereas large size classes $(5-7 \mathrm{~cm}$ and $>7 \mathrm{~cm})$, near the right riverside (left versus right, respectively: $14.0 \pm 0.7$ versus $15.8 \pm 0.7$ and $8.9 \pm 0.8$ versus $13.9 \pm 1.0)$. 
Table 2. Effects of different factors on size composition of fish, Model 3.

\begin{tabular}{|c|c|c|c|c|c|}
\hline \multicolumn{3}{|l|}{ Small } & \multicolumn{3}{|c|}{ Large } \\
\hline Effect & $F$ & d.f. & Effect & $F$ & d.f. \\
\hline$<3 \mathrm{~cm}$ & & & $5-7 \mathrm{~cm}$ & & \\
\hline LEVEL & 5.28 & $1,681.87 *$ & LEVEL & 4.23 & $1,695.75^{*}$ \\
\hline DIURN & 92.47 & $1,701.22 * * *$ & DIURN & 46.50 & $1,716.41 * * *$ \\
\hline SIDE & 40.70 & $1,336.81 * * *$ & SIDE & 15.65 & $1,327.78 * * *$ \\
\hline ZONE & 1.32 & $1,704.65$ & ZONE & 0.01 & $1,626.07$ \\
\hline $3-5 \mathrm{~cm}$ & & & $>7 \mathrm{~cm}$ & & \\
\hline LEVEL & 5.49 & $1,712.20 *$ & LEVEL & 12.74 & $1,689.71 * * *$ \\
\hline DIURN & 15.86 & $1,733.77 * * *$ & DIURN & 148.15 & $1,709.85^{* * *}$ \\
\hline SIDE & 4.55 & $1,321.56^{*}$ & SIDE & 67.19 & $1,331.30 * * *$ \\
\hline ZONE & 10.00 & $1,549.80^{* *}$ & ZONE & 0.08 & $1,658.42$ \\
\hline
\end{tabular}

LEVEL, water level reduction during the flood progress (high water versus low water); DIURN, diurnal period (day versus night); SIDE, riverside (left versus right); ZONE, river zone (upper versus down). Type II Wald $F$ tests with Kenward-Roger degrees of freedom (d.f.) are presented. See text for more explanations. ${ }^{*} P<0.05 ;{ }^{* *} P<0.01 ; * * * P<0.001$.

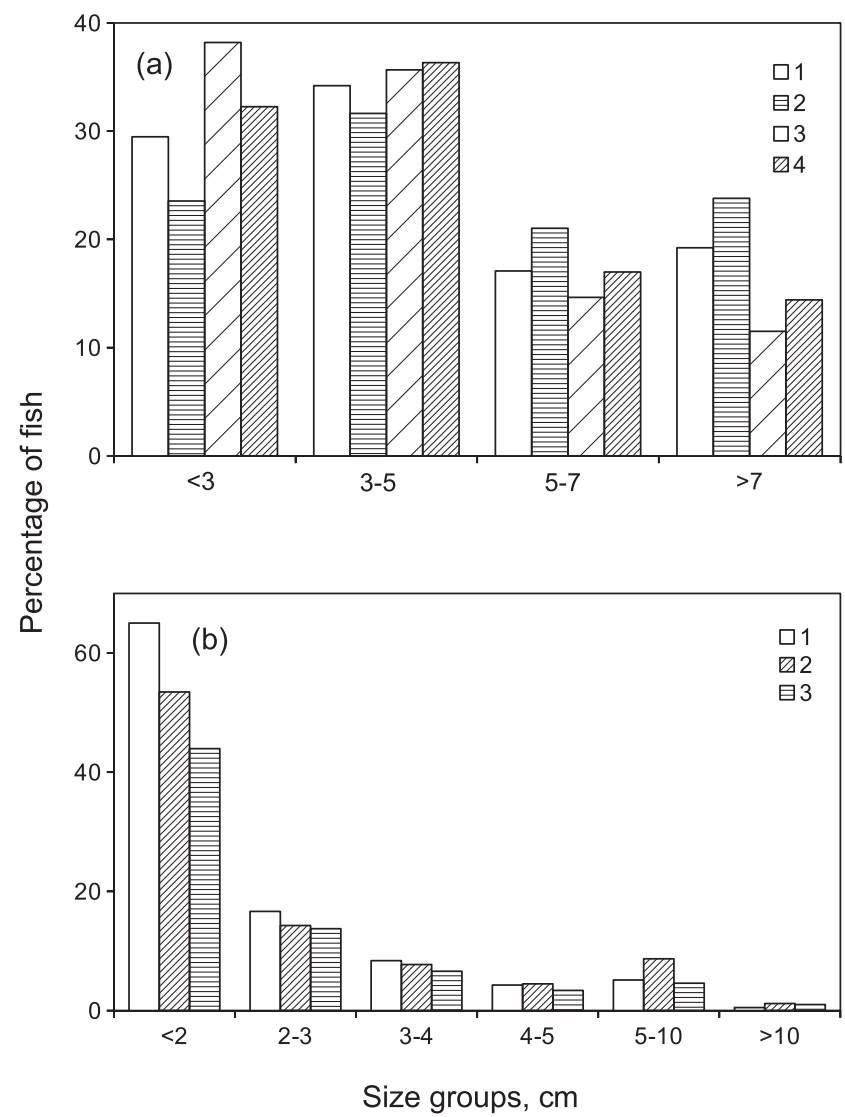

Fig. 4. Size composition of the fish in the main channel of the Irtysh River (a) and Varpak stream (b). Numbers in the legend (a): 1 and 2 refer to high water, 3 and 4, low water; 1 and 3 = day, 2 and $4=$ night; Numbers in the legend to (b) refer to dates: $1=09-18 / 06$ (high water), $2=19-28 / 06,3=29 / 06-09 / 07 / 2012$ (low water).

Our hydroacoustic data recorded in the Varpak stream (based on Netcor recording) indicated that fish moved both down and, surprisingly, also up along this stream. Even though the number of fish moving downstream was significantly higher (Wilcoxon: $V=462, P<0.001$ ), numerous fish moved upstream in all days of our observations (Fig. 5(a)). Visual observations indicated that the fish tended to move up the stream preferentially in proximity of its banks whereas downstream, in the stream mid-channel. The largest proportion of these fish was represented by early juveniles not exceeding $2 \mathrm{~cm}$ in body length (Fig. 4(b)). The number of fish migrating downstream towards the Irtysh River significantly negatively correlated with the illumination level (Pearson correlation coefficient: $r=-0.75, t=-5.32$, d.f. $=22$, $P<0.001)$, as did the number of fish moving upstream $(r=-0.56, t=-3.15$, d.f. $=22, P=0.005)$ : in both cases the fish predominantly tended to move at night (Fig. 5(b)).

We did not detect any significant correlation between the water level and the number of fish moving up $(r=0.34$, $t=1.94$, d.f. $=27, P=0.063)$ or down $(r=0.30, t=1.64$, d.f. $=27, P=0.113)$ the stream. But the level of the daily decrease of the flood water significantly correlated with the number of fish moving downstream $(r=0.45, t=2.56$, d.f. $=26, P=0.017)$ as well as upstream $(r=0.48, t=2.79$, d.f. $=26, P<0.01)$. A cross-correlation analysis indicated (Fig. 6) that movement of the fish-both downstream and upstream-was correlated with daily water level reduction at lags ranging from -7 to 0 days. However, the maxi mum cross-correlations in both cases occurred at 4 days (Fig. 6). This indicated that the fish migration responded to short-term fluctuations of the flood water level, but with the above time lag. Interestingly, the cross-correlation function for the number of fish migrating downstream versus upstream reached its maximum value at no lag (Fig. 6), further suggesting that they both may depend on the same common factor (water level in this case).

\section{Discussion}

The floodplain river represents a dynamic system of temporary and permanent flood plains, tributaries, streams, oxbows and other similar water bodies. Floodplains are typically characterized by high spatial heterogeneity and temporal variability (Ward et al., 2002), making them an ideal model for the study of various 

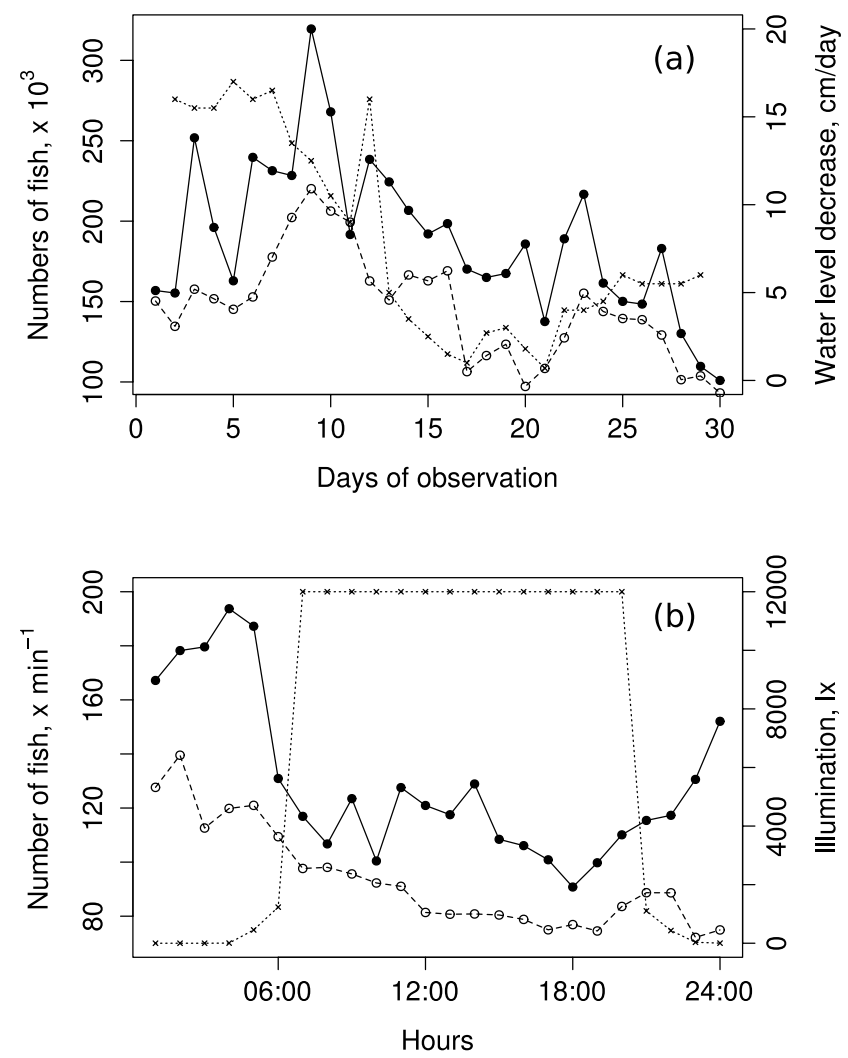

Fig. 5. (a) The numbers and direction of fish movements in the Varpak stream. Solid line with black circles = downstream, dashed line with open circles = upstream (left $Y$-scale); dotted line with crosses = daily decrease of the water level (right $Y$-scale). (b) Diurnal dynamics of fish movement in the Varpak stream. Solid line with black circles = downstream, dashed line with open circles = upstream (left $Y$-scale); dotted line with crosses $=$ illumination level (right $Y$-scale).

environmental effects on organisms (Ward et al., 2002; Tockner et al., 2010). Hydrological and ecological connectivity between them and the main river channel are the necessary condition for normal functioning of the whole ecosystem (Wolter and Bischoff, 2001; Amoros and Bornette, 2002; Nunn et al., 2010).

Flooding brings about dramatic changes to the river system, altering habitat mosaic (Stanford et al., 2005), modifying sedimentation, nutrient supply, current speed, water surface area and so on (Junk et al., 1989; Fernandes, 1997; Wolter and Bischoff, 2001). Thus, flooding significantly changes habitats of many fish species and triggers a range of their migrations. For example, adult fish migrate to the floodplain during the rising phase of the flood cycle for feeding and spawning; subsequently, at the receding phase, adults and the young go back to the main channel from the continuously draining habitats.

This study agrees with the previous research (Pavlov et al., 2010) that small juveniles represent a major component of fish populations in floodplain and channel areas of the Lower Irtysh. The downstream migration of juvenile fish, when they leave the flood plains and move down to the main channel, plays a principal role in the ecology of many freshwater fish species; mass downstream migration at night is well described in the literature (Thorpe and Morgan, 1978; Pavlov, 1994; Reichard et al., 2002). The increased occurrence of smaller juvenile fish observed at the end of the flood could reflect their more intense washout from the floodplain waterbodies in this period. Alternatively, it is likely that at night these juveniles are easily dragged by water current into the main channel and enter into the downstream migration (Pavlov 1994; Sonny et al., 2006), reducing their density in nearshore areas. This hypothesis is supported by our data from the Gornoslinkino hollow area indicating that at night juvenile fish predominantly appear in the middle of the river above the hollow.

We suggest that the large numbers of fish found in all near-surface areas of the Irtysh River (both riversides and the Gornoslinkino hollow area) at night may be accounted for by their active movement out of shelters such as nearshore vegetation and more intense downstream migration from tributaries typically occurring at night (Thorpe and Morgan, 1978; Pavlov, 1994; Reichard et al., 2002). At this time small juveniles would be easily dragged by the water flow into the main channel. Taking account of the dominant pattern of the Irtysh current immediately upstream of the Gornoslinkino hollow - the development of a huge swirl at the water surface just above a sharp drop-off of the bottom relief (Fig. 1) -we may expect that the migrating juveniles would be absorbed into this huge vortex and further dragged into the main channel.

The observed redistribution of fish between the upper and the down zones, such as their transition from left to right riverside at high water, may reflect dominant patterns of the current, depths and local ecological heterogeneity in the nearshore areas (Fig. 1). In the upper zone, smaller juveniles may accumulate near the left bank with slower current but may also be dragged by the intense current at the right bank upon their transition to the down zone (especially at night). The reverse (upstream) migration could also contribute to increased fish density off the right bank. Our visual observations indicated that a notable number of juvenile fish are actually moving upstream in the down zone off the right bank of the Irtysh River during the day. Such upstream migration may also aggregate fish and increase their density at the right riverside. It appears that local ecological conditions (e.g., those that determine differences in fish movements at the left and right riversides) affect the fish abundance in complex ways, and their overall effect represents an outcome of an interaction with the diurnal illumination cycle (day versus night) and, to a smaller degree, the level of the flood water. Nonetheless, overall fish density seemed to depend mainly on the diurnal illumination cycle and to much less degree reflected local environmental heterogeneity.

In this study, the largest proportion of the fish occurring in the Varpak stream moved downstream, towards the main channel of the Irtysh River. Nonetheless, quite many of them always moved in the opposite direction: upstream. Whereas the roles of lateral and two-way 

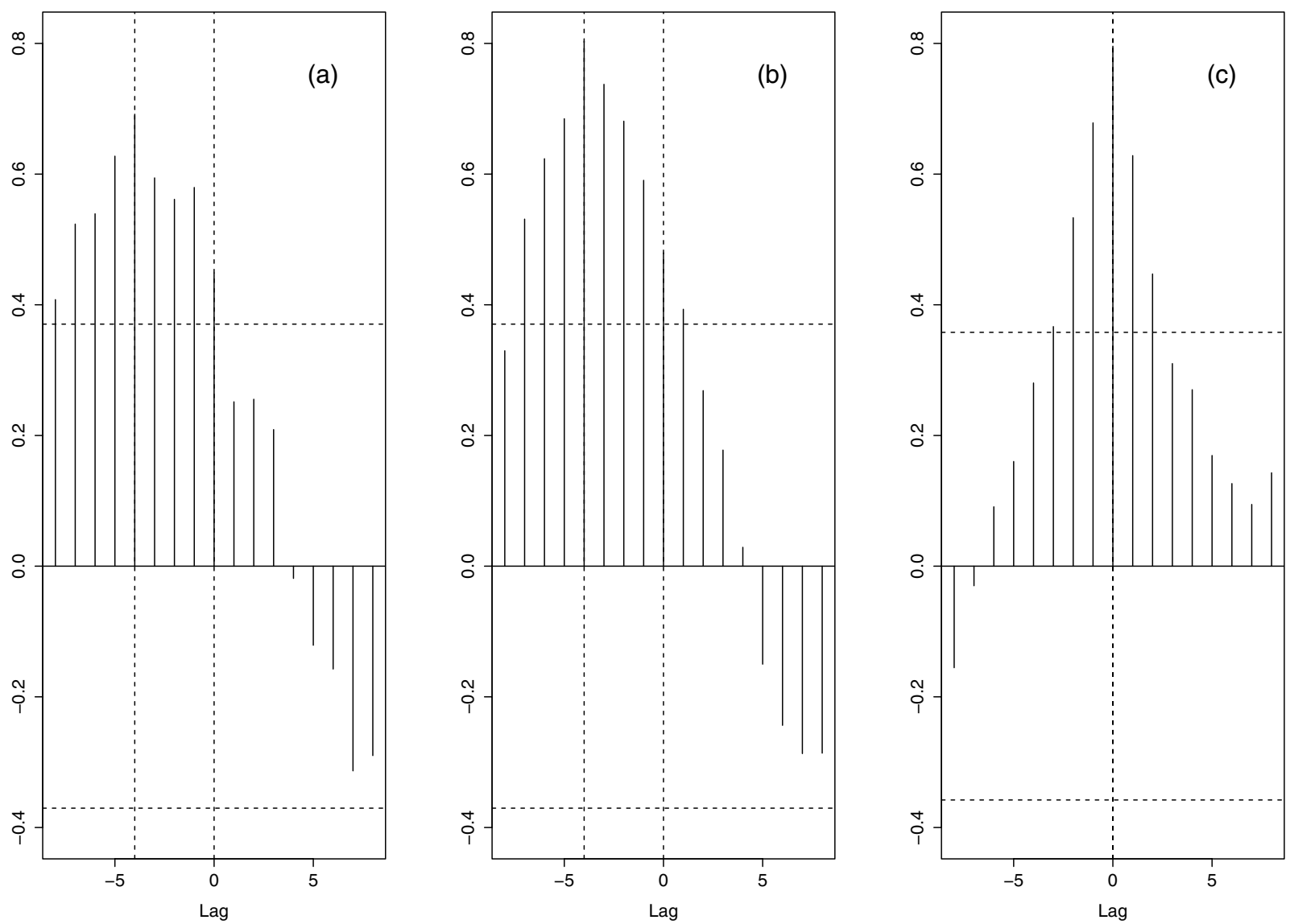

Fig. 6. Cross-correlation function for the numbers of fish and daily water level decrease: (a) downstream, (b) upstream (maximum correlation is reached at the lag $=4$ ). (c) Cross-correlation function for the number of fish moving upstream and downstream (maximum correlation reached at lag $=0$ ). Horizontal dashed lines depict the confidence level of the cross-correlations, vertical dashed lines point to lags 0 and -4 .

migrations of fish in floodplain areas have been studied (Fernandes, 1997; Hohausová et al., 2003; Welcomme et al., 2006; Nunn et al., 2010; Makrakis et al., 2012), mass upstream migration of juveniles appears unusual. Even though upstream migrations of juvenile fish have been occasionally documented (Yuma et al., 2000; Beckman and Larsen, 2005; Urabe, 2006), their mechanisms and adaptive significance are unclear. We are also unaware of any study reporting so large-scale upstream migration of juvenile fish. We hypothesize that as the flood progresses, drainage of upper floodplain waterbodies may trigger intense migration of early juveniles. They may directly respond to the reduction of their local habitat by entraining into the downstream migration. In such a case, the 4 days delay might just reflect the duration of the fish migration from the upper reaches of the stream. However, why the same response lag was observed in the fish moving upstream remains unexplained. An interesting hypothesis may involve active adaptive behavioural response of the fish to the water level fluctuations or other stimuli directly predicting or closely linked with it (e.g., weather condition, current speed, turbidity) but not directly caused by drainage of the local flood plain. This is not unrealistic because fish do respond to flow modifications (see Murchie et al., 2008 for a meta-analysis of the available literature). Consequently, juveniles may use one of two alternative strategies: either entrain into the downstream migration or actively use the last chances to exploit the rich food resources in the floodplain area. However, the efficiency of the latter strategy would depend on the fish swimming performance and their ability to move against the current (Pavlov, 1994; Sonny et al., 2006; Wolter and Sukhodolov, 2008). It is also likely that juvenile fish could alternate the two strategies, moving upstream during the day but downstream at night. In any case, our data point to a potentially important role of adaptive behavioural strategies as a mechanism of downstream migration of juvenile fish (Pavlov et al., 2007, 2008). We expect that further reports of upstream migration will appear as more studies involve tracking juvenile fish.

Our investigation demonstrated that diurnal illumination level always had the strongest main effect on fish density. Local ecological heterogeneity and the water level primarily determined dynamic re-distribution of fish via interactive rather than additive effects. As a result, we were unable to identify any local spatial area characterized by consistently heightened fish density. The Subarctic Siberian region is characterized by severe climatic conditions with strong seasonality. Therefore, large subarctic rivers, such as Irtysh, experience pronounced seasonal 
changes of the water temperature, water discharge and nutrient availability (Lyozin, 1999; Hrkal et al., 2006; Cai et al., 2008; Huang et al., 2012). It appears that such seasonal and diurnal cycles exert the major influences on the distribution and abundance of fish, whereas local habitat heterogeneity and complexity seem relatively unimportant.

Habitat structure and complexity plays an important role in shaping floodplain biota, including fish (Pusey et al., 1995; Amoros and Bornette, 2002; Hohausová et al., 2003; Rosso and Quiros, 2009). However, such effects are not always straightforward. For example, while spatial factors may sometimes be more important than seasonal (e.g., Ostrand and Wilde, 2002; Araújo et al., 2009), relative role of spatial and non-spatial effects may differ in different locations (e.g., Idaho versus Ohio; Kautza and Sullivan, 2012). Furthermore, in relatively high latitude temperate rivers (e.g., Sveden; Lepori et al., 2005), local environmental heterogeneity may not significantly structure fish assemblages. Finally, relative contribution of spatial and temporal factors may change during the flood cycle (Scarabotti et al., 2011). Highly variable environments should strongly favour generalist species (Poff and Allan, 1995) which would be relatively tolerant to spatial and temporal (including seasonal) effects, so that their abundance would not respond much to these environmental changes (Araújo et al., 2009). Most fish in our study were represented by generalist cyprinids. We thus suggest that the high environmental variability in lower Irtysh dampens local environmental effects on fish assemblages. Similar dynamism with little effects of local habitat heterogeneity may be expected in other systems that are subject to pronounced seasonal and diurnal (and other non-seasonal) environmental variability.

This pattern may have serious implications for the management and conservation. For example, spatially localized conservation efforts are likely to be relatively inefficient because there are no significant "key" areas and habitats attracting most of the fish in the main channel. Instead, conservation management efforts should take into consideration the diurnal cycle. The role of floodplain tributaries as juvenile fish nurseries should also be emphasized. Upstream migration of juvenile fish in floodplain streams and probably in the main channel should also be given more consideration. For example, we should allow the passage of small fish both up- and downstream in case of artificial obstacles. The biological role of mass upstream migration of juvenile fish deserves further research.

Acknowledgements. We are grateful to two anonymous reviewers for many valuable critical comments on the paper. This work was supported by the Russian Foundation for Basic research (grants 13-04-00060a and 13-04-10056k); Programme of the Division of Biological Sciences of the Russian Academy of Sciences "Biological resources of Russia: dynamics under global climatic and anthropogenic effects"; Programme "Leading scientific schools" (NSh-719.2012.4).

\section{References}

Agostinho A.A., Gomes L.C., Verıssimo S. and Okada E.K., 2004. Flood regime, dam regulation and fish in the Upper Paraná River: effects on assemblage attributes, reproduction and recruitment. Rev. Fish Biol. Fish., 14, 11-19.

Amoros C. and Bornette G., 2002. Connectivity and biocomplexity in waterbodies of riverine floodplains. Freshwat. Biol., 47, 761-776.

Araújo F.G., Pinto B.C.T. and Teixeira T.P., 2009. Longitudinal patterns of fish assemblages in a large tropical river in southeastern Brazil: evaluating environmental influences and some concepts in river ecology. Hydrobiologia, 618, 89-107.

Beckman B.R. and Larsen D.A., 2005. Upstream migration of Minijack (Age-2) Chinook salmon in the Columbia River: behavior, abundance, distribution, and origin. Trans. Am. Fish. Soc., 134, 1520-1541.

Borisenko E.S., 2008. In situ measurement of fish target strength using scanning hydroacoustic systems. In: Gerasimov Yu.V., Bazarov M.I., Malin M.I. and Tsvetkov A.I. (eds.), Materials of The Russian Conference "Hydroacoustic Ionvestigations in Inland Waters", Institute of the Biology of Inland Waters, Russian Academy of Sciences, Borok, 2008. Printhouse, Moscow, 12-19.

Borisenko E.S., Degtev A.I., Mochek A.D. and Pavlov D.S., 2006. Hydroacoustic characteristics of mass fishes of ObIrtish basin. J. Ichthyol., 46, S227-S234.

Borisenko E.S., Gusar A.G. and Goncharov S.M., 1989. The target strength dependence of some freshwater species on their length-weight characteristics. Proc. Inst. Acoust., 11, 27-34.

Borisenko E.S., Mochek A.D. and Pavlov D.S., 2011. Hydroacoustic method for the study of fisheries resources in inland waters. In: Golovanov V.K., Gerasimov Yu.V. and Shatunovskii M.I. (eds.), Current State of Inland Bioresources, Vol. 1. Akvaros, Moscow, 74-85.

Brehmer P., 2003. New applications of hydroacoustic methods for monitoring shallow water aquatic ecosystems: the case of mussel culture grounds. Aquat. Living Resour., 16, 333-338.

Cai Y., Guo L., Douglas T.A. and Whitledge T.E., 2008. Seasonal variations in nutrient concentrations and speciation in the Chena River, Alaska. J. Geophys. Res., 113, G03035.

Fernandes C.C., 1997. Lateral migration of fishes in Amazon floodplains. Ecol. Freshwat. Fish, 6, 36-44.

Frouzova J., Kubecka J. and Mrkvicka T., 2011. Differences in acoustic target strength pattern between fish with one- and two-chambered swimbladder during rotation in the horizontal plane. Fish. Res., 109, 114-118.

Hohausová E., Copp G.H. and Jankovský P., 2003. Movement of fish between a river and its backwater: diel activity and relation to environmental gradients. Ecol. Freshwat. Fish, 12, 107-117.

Hrkal Z., Gadalia A. and Rigaudiere P., 2006. Will the river Irtysh survive the year 2030? Impact of long-term unsuitable land use and water management of the upper stretch of the river catchment (North Kazakhstan). Environ. Geol., 50, 717-723.

Huang F., Xia Z., Li F., Guo L. and Yang F., 2012. Hydrological changes of the Irtysh River and the possible causes. Water Resour. Manag., 26, 3195-3208. 
Jackson D.A., Peres-Neto P.R. and Olden J.D., 2001. What controls who is where in freshwater fish communities - the roles of biotic, abiotic, and spatial factors. Can. J. Fish. Aquat. Sci., 57, 157-170.

Junk W., Bayley P. and Sparks R., 1989. The flood pulse concept in river-floodplain systems. In: Proceedings of the International Large River Symposium. Can. Spec. Publ. Aquat. Sci., 106, 110-127.

Kautza A. and Sullivan S.M.P., 2012. Relative effects of localand landscape-scale environmental factors on stream fish assemblages: evidence from Idaho and Ohio, USA. Fund. Appl. Limnol., 180, 259-270.

Kenward M.G. and Roger J.H., 1997. Small sample inference for fixed effects from restricted maximum likelihood. Biometrics, 53, 983-997.

Knudsen F.R. and Sægrov H., 2002. Benefits from horizontal beaming during acoustic survey: application to three Norwegian lakes. Fish. Res., 56, 205-211.

Kudryavtsev V.I. and Borisenko E.S., 2009. Device for the Estimation of Fish Sizes During their Location. Russian Patent RU 2367151 C1, A01K61/00 (2006.01), Russian Federal Institute of Fisheries and Oceanography, VNIRO.

Lepori F., Palm D., Brännäs E. and Malmqvist B., 2005. Does restoration of structural heterogeneity in streams enhance fish and macroinvertebrate diversity? Ecol. Appl., 15, 2060-2071.

Lucas M.C., Baras E., Thom T.J., Duncan A. and Slavík O. (eds.), 2001. Migration of Freshwater Fishes, Blackwell, Oxford.

Lucas M.C., Walker L., Mercer T. and Kubecka J., 2002. A review of fish behaviours likely to influence acoustic fish stock assessment in shallow temperate rivers and lakes. Technical Report W2-063/TR/1. Environment Agency, Rio House, Waterside Drive, Aztec West, Almondsbury, Bristol, UK.

Lyozin V.A., 1999. Rivers of the Khanty-Mansi Autonomous Okrug. A reference book, Vektor Book, Tyumen (In Russian).

Makrakis M.C., Miranda L.E., Makrakis S., Fontes Júnior H.M., Morlis W.G., Dias J.H.P. and Garcia J.O., 2012. Diversity in migratory patterns among Neotropical fishes in a highly regulated river basin. J. Fish Biol., 81, 866-81.

Murchie K.J., Hair K.P.E., Pullen C.E., Redpath T.D., Stephens H.R. and Cooke S.J., 2008. Fish response to modified flow regimes in regulated rivers: research methods, effects and opportunities. River Res. Appl., 24, 197-217.

Nunn A.D., Harvey J.P. and Cowx I.G., 2007. Benefits to $0+$ fishes of connecting man made waterbodies to the lower River Trent, England. River Res. Appl., 23, 361-376.

Nunn A.D., Copp G.H., Vilizzi L. and Carter M.G., 2010. Seasonal and diel patterns in the migrations of fishes between a river and a floodplain tributary. Ecol. Freshwat. Fish, 19, 153-162.

Ostrand K. and Wilde G., 2002. Seasonal and spatial variation in a prairie stream-fish assemblage. Ecol. Freshwat. Fish, 11, 137-149.

Pavlov D.S., 1994. The downstream migration of young fishes in rivers: mechanisms and distribution. Folia Zool., 43, 193-208.

Pavlov D.S. and Mochek A.D., 2009. Fish distribution in river systems as a dynamic phenomenon. Usp. Sov. Biol., 129, 528-537.
Pavlov D.S., Lupandin A.I. and Kostin V.V., 2007. Mechanisms of Downstream Migration of Young Fish Living in Rivers, Nauka, Moscow (In Russian).

Pavlov D.S., Mikheev V.N., Lupandin A.I. and Skorobogatov M.A., 2008. Ecological and behavioural influences on juvenile fish migrations in regulated rivers: a review of experimental and field studies. Hydrobiologia, 609, $125-138$.

Pavlov D.S., Mochek A.D., Borisenko E.S. and Degtev A.I., 2009. Investigation of spawning migrations of commercial fish species using hydroacoustic systems. In: Biological Resources of the White Sea and Inland Water Bodies of the North of Europe. Proceedings of the 18th International Conference, Petrozavodsk, Karelia, Russia. Petrozavodsk, 391-398.

Pavlov D.S., Mochek A.D., Borisenko E.S. and Degtev A.I., 2010. Hydroacoustic investigation of taxonomic composition and of vertical distribution of fish in the riverbed depression. J. Ichthyol., 50, 969-976.

Pinherio J.C. and Bates D.M., 2000. Mixed-Effects Models in S and S-PLUS, Springer, New York.

Poff N. and Allan J., 1995. Functional organization of stream fish assemblages in relation to hydrological variability. Ecology, 76, 606-627.

Pusey B.J., Arthington A.H. and Read M.G., 1995. Species richness and spatial variation in fish assemblage structure in two rivers of the Wet Tropics of Northern Queensland, Australia. Environ. Biol. Fish., 42, 181-199.

R Core Team, 2013. R: A Language and Environment for Statistical Computing, http://www.r-project.org.

Rakowitz G., Berger B., Kubecka J. and Keckeis H., 2008. Functional role of environmental stimuli for the spawning migration in Danube nase Chondrostoma nasus (L.). Ecol. Freshwat. Fish, 17, 502-514.

Reichard M., Jurajda P. and Ondračková M., 2002. The effect of light intensity of the drift of young-of-the- year cyprinid fishes. J. Fish Biol., 61, 1063-1066.

Rosso J. and Quiros R., 2009. Interactive effects of abiotic, hydrological and anthropogenic factors on fish abundance and distribution in natural run of the river shallow lakes. River Res. Appl., 25, 713-733.

Scarabotti P.A., López J.A. and Pouilly M., 2011. Flood pulse and the dynamics of fish assemblage structure from neotropical floodplain lakes. Ecol. Freshwat. Fish, 20, 605-618.

Simmonds J. and MacLennan D. (eds.), 2005. Fisheries Acoustics. Blackwell, Oxford.

Sonny D., Jorry S., Wattiez X., and Philippart J.-C., 2006. Interannual and diel patterns of the drift of cyprinid fishes in a small tributary of the Meuse River, Belgium. Folia Zool., 55, 75-85.

Stanford J.A., Lorang M.S. and Hauer F.R., 2005. The shifting habitat mosaic of river ecosystems. Verh. - Int. Ver. Theor. Angew. Limnol., 29, 123-136.

Tátrai I., Specziár A., György A.I. and Bíró P., 2009. Comparison of fish size distribution and fish abundance estimates obtained with hydroacoustics and gill netting in the open water of a large shallow lake. Ann. Limnol. - Int. J. Limnol., 44, 231-240.

Thorpe J.E. and Morgan R.I.G., 1978. Periodicity in Athlantic salmon Salmo salar L., smolt migration. J. Fish Biol., 12, 541-548. 
Tockner K., Lorang M.S. and Stanford J.A., 2010. River flood plains are model ecosystems to test general hydrogeomorphic and ecological concepts. River Res. Appl., 26, 76-86.

Urabe M., 2006. Demonstration of migration of juvenile cyprinid fish using parasite biomarkers. Landsc. Ecol. Eng., 2, 209-216.

Van den Brink F., 1996. Biodiversity in the lower Rhine and Meuse river-floodplains: its significance for ecological river management. Netherlands J. Aquat. Ecol., 30, 129-149.

Vincent W., 2008. Introduction to the limnology of high latitude lake and river ecosystems. In: Vincent W.F. and LaybournParry J. (eds.), Polar Lakes and Rivers - Limnology of Arctic and Antarctic Aquatic Ecosystems. Oxford University Press, Oxford, 1-23.

Ward J.V., Tockner K., Arscott D.B. and Claret C., 2002. Riverine landscape diversity. Freshwat. Biol., 47, 517-539.

Ward J.V., Tockner K. and Schiemer F., 1999. Biodiversity of floodplain river ecosystems: ecotones and connectivity. Regul. Rivers Res. Manag., 15, 125-139.
Warton D. and Hui F., 2011. The arcsine is asinine: the analysis of proportions in ecology. Ecology, 92, 3-10.

Welcomme R.L., Winemiller K.O. and Cowx I.G., 2006. Fish environmental guilds as a tool for assessment of ecological condition of rivers. River Res. Appl., 22, 377-396.

Winfield I.J., Emmrich M. and Guillard J., 2013. Guidelines for standardisation of hydroacoustic methods. Deliverable 3-4.3. Water bodies in Europe: integrative systems to assess ecological status and recovery, Seventh Framework Programme, 1-30.

Wolter C. and Bischoff A., 2001. Seasonal changes of fish diversity in the main channel of the large lowland River Oder. Regul. Rivers Res. Manag., 17, 595-608.

Wolter C. and Sukhodolov A., 2008. Random displacement versus habitat choice of fish larvae in rivers. River Res. Appl., 24, 661-672.

Yuma M., Maruyama A. and Rusuwa B., 2000. Behavior and distribution of upstream-migrating juvenilerhinogobius sp. (The orange form). Ichthyol. Res., 47, 379-384. 